\title{
Smallpox and Bioterrorism: History and Evaluation of Current State and Medical Knowledge
}

\author{
Buonsenso $D^{1 *}$, Gargiullo $L^{2}$, Cataldi $L^{3}$, Ranno $\mathrm{O}^{4}$ and Valentini $\mathrm{P}^{4}$ \\ ${ }^{1}$ Department of Pediatrics, Catholic University of the Sacred Heart, L,go A, Gemelli, 8, 00168, Rome, Italy \\ ${ }^{2}$ Division of Neonatology, Department of Pediatric Sciences, Catholic University of Sacred Heart, Rome, Italy \\ ${ }^{3}$ Istituto di Clinica Pediatrica, Università Cattolica del Sacro Cuore (UCSC), Rome \\ ${ }^{4}$ Department of Pediatrics, A. Gemelli University Hospital, Catholic University of the Sacred Heart, Largo Gemelli 8, 00168 Rome, Italy
}

\begin{abstract}
Introduction: Although smallpox has been declared eradicated in 1980, we still have to consider it a global threat, provided the terrorist and bioterrorist attacks of September 2001 and the ongoing precarious worldwide political situation.

Materials and Methods: We performed an email-based survey, composed of 6 YES/NO questions aimed to evaluate current basic smallpox knowledge among medical students, residents and specialists.

Results: A total of 172 people from 22 different countries replied to our email. 111 were students (64.5\%), 38 residents $(22.1 \%)$, and 23 specialists (13.4\%).

More than half participants $(54.6 \%)$ stated they had never had a lecture on smallpox during medical school and showed lack of knowledge about basic concepts that could be useful in the event of a bioterrorist attack (recognition of typical lesions, natural history, differential diagnosis, and treatment). Moreover, medical students showed a significant lower knowledge if compared to graduates regarding basic smallpox clinical questions $(P<0.05)$.
\end{abstract}

Conclusions: Our findings support the hypothesis that since its eradication, there has been a general decay of basic smallpox knowledge. These observations rise concerns on medical preparedness to respond to a bioterrorist attack.

\section{Introduction}

Smallpox is a member of the family Poxviridae, subfamily Chordopoxvirinae, and genus orthopoxvirus. Poxviruses are single, linear, double-stranded DNA viruses. Several poxviruses cause disease in humans, such as molluscum contagiosum, smallpox and monkeypox. [1] Because smallpox lacks a known non-human animal reservoir, its origin as a human pathogen is still mysterious. It has been suggested that smallpox was transferred to the human population from an African rodent host [2].

The respiratory tract is the usual route of entry for smallpox. After a first phase of viremia, the virus multiplies in the reticuloendothelial system. A second viremia let the virus invade the mouth, pharynx and skin, leading to the beginning of the characteristic lesions. The prodromal phase follows an incubation period of 7-17 days; it lasts two to four days, and it's characterized by severe headaches, backaches, and fever. [3] The temperature usually rises to more than $40^{\circ} \mathrm{C}$ and then subsides over a period of two to three days. Enanthema over the tongue, mouth, and oropharynx precedes the rash by a day. These lesions quickly break down and shed large amounts of virus into oral secretions. In this stage a person becomes infectious to others. [4] The rash progresses from macules to vesicles to umbilication and crusting over 7-14 days. Patients are most infectious during the first week of rash [4].

The World Health Organization (WHO) has classified five types of smallpox. [1] The "ordinary" type, or variola major, accounts for nearly $90 \%$ of cases, with a case fatality rate of $30 \%$. [3,5] The "modified" type (variola minor) is rarely fatal. The "flat" type has a with $97 \%$ fatality rate among unvaccinated patients. The "hemorrhagic" smallpox $(<3 \%$ of cases) is almost invariably lethal. The "variola sine eruptione" type, in previously vaccinated contacts or in infants with maternal antibodies, is usually asymptomatic or with flu-like symptoms [6].
Smallpox needs to be differentiated from other diseases manifestating with vesicular or pustular rash. Historically, the main differential diagnosis has been with chickenpox. Unlike chickenpox, smallpox lesions are: characteristically all at the same stage of development, umbillicated and distributed centrifugally, therefore affecting primarily face and distal limbs, including palms and soles. Additional diseases to take into account include: measles, scarlet fever, and rubella (macular/papular stage); impetigo, disseminated herpes zoster, herpes simplex, human monkeypox, and molluscum contagiosum (vesicular/pustular stage); secondary syphilis, enteroviral infections, and scabies/insect bites (both stages); meningococcemia, rickettsial infections, and gram-negative septicaemia (hemorrhagic smallpox) [7]. Smallpox infection confers lifelong immunity, even though it usually lasts no more than 25-30 years [8].

Although specific antiviral therapies are being developed, none of them is currently licensed for this indication[9]. Among these drugs, cidofovir showed the best results, but it causes renal toxicity and there is no evidence that it would be more effective than vaccination [7]. The US has at least 2 new antivirals under development and in line for FDA approval for treatment of smallpox.

${ }^{*}$ Corresponding author: Buonsenso D, Department of Pediatrics, Catholic University of the Sacred Heart, L,go A, Gemelli, 8, 00168, Rome, Italy, E-mail: danilobuonsenso@gmail.com

Received October 08, 2011; Accepted November 15, 2011; Published November 19, 2011

Citation: Buonsenso D, Gargiullo L, Cataldi L, Ranno O, Valentini P (2011) Smallpox and Bioterrorism: History and Evaluation of Current State and Medical Knowledge. J Clinic Res Bioeth S3:001. doi:10.4172/2155-9627.S3-001

Copyright: (c) 2011 Buonsenso D, et al. This is an open-access article distributed under the terms of the Creative Commons Attribution License, which permits unrestricted use, distribution, and reproduction in any medium, provided the original author and source are credited. 
The United States, Department of Health and Human Services issued the first request for procurement of a smallpox antiviral drug for inclusion in the Strategic National Stockpile (RFP-BARDS-09-35) in March of 2009. Nevertheless, the indication for this drug is for treatment of smallpox which is defined as initiating dosing at the time of lesional disease. Therefore successful utilization of the drug would require recognition of smallpox lesions. Will the physician seeing the primary case recognize the disease and request the drug from the Strategic National Stockpile in time to make the difference? It is important to point out that drugs are not intended to replace vaccination in the general population.

Currently, the available smallpox vaccine is ACAM2000, a liveattenuated vaccinia virus closely related to cowpox. Since its approvation in September 2007, 192.5 million doses have been stockpiled in the USA. [10] The production of the previously used vaccine (Dryvax) was stopped in the 1980s. [7] The vaccine should be administered by trained, vaccinated personnel using the scarnification technique with bifurcated needles. Recently, new efforts have been focusing on the vaccinia strain MVA, (aiming to yield an effective vaccine also safe for immunocompromised individuals), and on subunit vaccines. [11] Nevertheless, MVA is not the only alternative vaccine under development, although it is the choice for some European countries.

\section{History of smallpox}

Observations of skin lesions consistent with smallpox on Egyptian mummies dating from 1100 to 1580 B.C. [1,3] initially suggested that ancient Egypt could have been the earliest smallpox endemic region. However, smallpox researchers challenged this theory because of the absence of smallpox descriptions from books of the Old and New Testament and from the Greek and Roman literature.

First descriptions of smallpox-like disease in medical writings have been found in ancient China (1122 B.C.) and India (about 1500 B.C.), [3] but the earliest unmistakable descriptions of smallpox first appeared in the $4^{\text {th }}$ century A.D. in China, in the $7^{\text {th }}$ century A.D. in India and in the Mediterranean, and in the $10^{\text {th }}$ century A.D. in southwestern Asia [1]. In the $15^{\text {th }}$ century, the term "smallpox" was coined to differentiate it from syphilis.

In the early 1500s, Spanish adventurers under Hernando Cortez landed on the Yucatan Coast and marched to Tenochtitlan, carrying with them a smallpox infected slave. Over the next year the hueyzahautal (great eruption) raged over central America, and native American communities experienced case-fatality rates of $70 \%$ or more after virus introduction [12].

The disease had probably not reached the New World before the Spanish colonization. Millions of people in central Mexico and subsequently South America died during the first year of the hueyzahautal, destroying the Aztec and Inca empires. Francisco Pizarro, who continued Spanish conquests of South America in the 1530 s, is alleged to have undertaken a bioterrorist attack on native people using smallpox contaminated blankets [13].

In the early 1700s, Lady Mary Montagu, [12] brought to Europe the technique of "variolation", the inoculation into the skin of a healthy subject of material from smallpox pustules. The son of Caroline of Ansbach was the first person to be inoculated. Nevertheless, this procedure had important side effects, including death.

Edward Jenner introduced immunization against smallpox with material obtained from cowpox lesions. In 1798, he published the
"Inquiry Into the Causes and Effects of Variolae Vaccinae", in which he suggested that farm workers appeared to be immune to smallpox because of previous cowpox infection. This led him to develop the practice of vaccination: on May 14, 1796, he used material from a cowpox lesion on the hand of a milkmaid called Sarah Nelmes to vaccinate a farm boy named James Phipps.

Even though Jenner is honoured of being the discoverer of vaccination, it is probable that Benjamin Jesty, a farmer, has been the first person to have used material from cowpox pustules in 1774 to inoculate his family [14].

Although there was widespread opposition to the vaccination, the practice became widely accepted and eventually used worldwide. In 1801, Jenner predicted that "It now becomes too manifest to admit of controversy that the annihilation of the smallpox [...] must be the final result of this practice" [15].

Almost 200 years later, on 8 May 1980, Dr A-R. A. Al-Awadi, president of the $33^{\text {rd }}$ World Health Assembly, read: "Having considered the development and results of the global program on smallpox eradication initiated by WHO in 1958 and intensified since 1967 [...] Declares solemnly that the world and its people have won freedom from smallpox". The last notified natural case happened in Somalia in 1977 while the last fatal case was that of Mrs Janet Parker, who died in Birmingham, England, on 11 September 1978, after being infected by virus that had escaped from a laboratory [16]

\section{Monkeypox}

Monkeypox is another poxvirus reported in the African rainforests, that causes human smallpox-like disease through direct contact with infected animals or humans (squirrels and rodents) [17]. In 2003, a few cases have occurred in USA, in association with imported African rodents [18].

Increased prevalence in humans (20-fold increase in the last 20 years), particularly among immunocompromised patients, may also provide the opportunity for monkeypox virus to acquire mutations that increase its fitness in human hosts [19].

The emergence of human monkeypox could become a serious public health alarm. This arise also one more concern: could it be used as a source for the development of bioengineered smallpox-related virus to be used as a weapon of bioterrorism?

\section{Smallpox and bioterrorism}

The intentional release of anthrax in the United States in 2001, the destruction of the Twin Towers and other acts of terrorism have highlighted the possibility of intentional release of smallpox by terrorists. Moreover, the decline in the immunity to smallpox, due to the abandonment of vaccination in the late 1970s, has made the virus more attractive to terrorists. [20] We still do not know if any smallpox stocks exist outside of the two WHO-approved repositories (the CDC, in Atlanta, and VECTOR in Koltsovo, Novosibirsk). Modern technologies of DNA gene synthesis have now made readily achievable and quite simple the possibility of developing biological weapons [21]

The CDC has designated 3 categories $(\mathrm{A}, \mathrm{B}, \mathrm{C})$ of biological agents Smallpox is included among Category A, which includes the highestpriority agents, because of their capability of being disseminated or transmitted person-to-person easily (causing high rates of mortality, public panic and social disruption) and also because they require special action for public health preparedness. [22] In 1994, Soviet experts have 
concluded that smallpox headed the list, followed closely by anthrax and plague. [23] Smallpox is therefore worldwide acknowledged to be an attractive bioterrorist weapon.

Pre-emptive selected vaccination of public health and security workers has been initially suggested in order to limit the spread of a possible bioterrorist attack, but this would not be cost-effective and it might be potentially harmful. Therefore, the only cost-effective action to limit a potential attack would be a rapid and well-organized response based on case-finding, isolation, and ring vaccination [24].

\section{The effect of the abandonment of vaccination on bioterrorist- related outbreaks}

The smallpox vaccination stopped about a quarter of a century ago; as a consequence, nowadays $80 \%$ of the population is susceptible to infection. Therefore, the prominent question is how this could affect the size of an outbreak. The most important factor is the effective reproductive rate $(\mathrm{R})$, that is the average number of secondary cases infected by a primary case. During smallpox era, the secondary attack rate was $58.4 \%$ in nonvaccinated household contacts and $3.8 \%$ in previously vaccinated contacts. [1] Even though Gani and Leach [25] estimated a current $\mathrm{R}$ of 5.5 for community-acquired smallpox and of 10 if hospital-acquired cases are included (demonstrating the importance of spreading in hospitals), it remains difficult nowadays to predict the exact attack rates that would result from person-to-person transmission after intentional release of smallpox.

\section{What to do in response to bioterrorism}

A successful response require political organization and preparedness and adequate resources. It is likely that the first appearance of smallpox cases would happen in emergency rooms and in general practice officers. It is also likely that, at that moment, closer contacts and household would be infected as well. It is thus of fundamental importance for health care providers to reach a proper diagnosis and initiate the right preventive and therapeutic measures in the shortest lapse of time. Therefore, clinician preparedness is the first and probably most important step in response to bioterrorism.

Since 2001, a number of societies have provided training opportunities in peer-reviewed journals and meetings. USA alone has spent $\$ 126$ million in the effort of improving clinician awareness, introducing innovative training in bioterrorism in six medical schools. However, no follow-up report to evaluate knowledge improvement has been made since 2003 [26].

A key point in allowing physicians and general practitioners to perform smallpox diagnoses is the laboratory confirmation of a suspected case. The Department of Health and Human Services has established the Laboratory Response Network, which is composed of laboratories that can rule out the presence of biological threat agents in Biosefety Level (BSL) 1 or 2, laboratories that function at up to the BSL3 for further investigations and laboratories capable of functioning at the BSL-4 for final confirmation of the agent. However, there are still public health laboratories that lack sufficient capabilities to test for biological weapons [26].

Hospital preparedness is also crucial. It has been estimated that hospitals should have the capacity to support the infectious disease standard of 500 cases per million population, [26] negative-air-pressure rooms, a sufficient number of N95 (or higher-degree) respirators, as well as other protective equipment (gowns, gloves, eye protections). However, most hospitals have no such precautions.
After the recognition of a case, an adequate response would require the establishment of a strong communication and collaboration between local, state and federal levels, which is still suboptimal in many countries, including USA [27].

After identification and isolation of cases, their close contacts must be identified and vaccinated as soon as possible, preferably within 3 days of exposure to prevent or at least significantly reduce the severity of the disease [28].

Even though only a few people would be infected, there would be an immediate request for vaccination. USA has a large stock of vaccine, but most countries have little or none. Even though a small number of doses might be needed to vaccinate only close contacts of confirmed cases, public anxiety would be such that there would be an enormous, not-affordable request for vaccination, as happened after the H1N1 influenza virus pandemy. To date, there is only a limited manufacturing capacity to produce additional vaccine, and only in a few countries [26].

A major challenge would be to institute measures to avoid panic, a key point that still is neglected by Institutions. The role of medias would be vital, as crucial would be to keep the normal day-to-day activities, not invoking strong quarantine measures, closure of airports (or transportation network in general) or forbidden entry or departure from cities, as happened after the 2003 SARS outbreak. Experience has shown that these measures, overall quarantine, are seldom effective and often lead to other problems, as many would flee from the area or deny the presence of cases within family or friends, precluding appropriate control measures [29].

\section{Would we recognize smallpox?}

Since its eradication, physician's memory of smallpox as a clinical entity and the ability of diagnosing it has certainly decayed. In this regard, the Todmorden outbreak of 1953, finely described by Pennington, [16] provides an excellent example. The last fatal case of smallpox reported in Todmorden, England, was described in 1893 , and there had been no other cases recorded since the 1920s. The Todmorden outbreak of 1953 started out with J., the first identified person with smallpox who recovered without being diagnosed. $\mathrm{He}$ infected his wife and three workers (H., A.J., and N.). Two of these people died undiagnosed; for the other two, smallpox was only recognized very late and only after they had infected others with whom they had had contact. J.'s wife died because of "toxaemia due t o acute enteritis". H. died because of bronchopneumonia, his son and daughter because of "influenza". H. also infected T.B., who died with a petechial rash, diagnosed as severe scarlet fever. A.J. developed severe malaise, frontal headache and fever, and a herpetic lesion on his upper lip. A dermatologist made a provisional diagnosis of generalized herpes and A.J. was admitted to a district general hospital where he infected three patients in nearby beds and an ambulant patient. At home he had infected his wife, his daughter, and three visitors. N.'s illness was initially misinterpreted as chickenpox. His wife died of fulminant smallpox. Mrs B. was diagnosed as having acute leukaemia. A postmortem diagnosis of smallpox was performed to all these patients. Other emblematic examples are the 1970 outbreak in Germany, [30] and the 1972 outbreak in Yugoslavia [1]. A more recent case of misdiagnosis of vaccinia infection occurred in 2008 in a 28 month old child with failure to thrive syndrome (infected by his father who was vaccinated with ACAM2000), which almost caused the child his life [31]. These outbreaks illustrate the difficulties of diagnosing smallpox in non-endemic areas in pre-eradication times. 
What would happen if smallpox virus were to be deliberately released today in a modern, crowded city? In order to find an answer to that question, we performed an email-based survey, composed of 6 YES/NO questions aimed to evaluate the knowledge of basic concepts about smallpox. The six questions were: 1) have you ever had in your medical school at least a lecture (at least one hour long) about smallpox? 2) have you ever seen at least 3 different images of smallpox lesions? 3) do you know the natural history of smallpox? 4) do you know which diseases could be included in the differential diagnosis of smallpox? 5) do you know whether exist a treatment of proven efficacy and safety against smallpox? 6) do you know whether exist an effective and safe vaccine against smallpox?

The email was primarily sent to randomly-chosen medical students, residents and specialists of our Institution. Everyone had the possibility to forward the email to colleagues, regardless of their living countries. For every participant, the name of the medical school, the country, the year they started university and the current position were recorded.

The aim of our study was to evaluate current basic smallpox knowledge among medical students, residents and specialists, assessing any difference between current medical students and graduates (both residents and specialists).

Statistical analyses were performed using $\chi^{2}$ test. $P<0.05$ were considered statistically significant.

A total of 172 people replied to our email. 111 were students (64.5\%), 38 residents (22.1\%), and 23 specialists (13.4\%). The majority of participants were from Italy $(114,66.3 \%)$, followed by Belgium (nine), Czech-Republic (seven), the Netherlands (six), Spain, and USA (five each), Brazil (four), Germany, and South Africa (three each), Portugal, United Kingdom, and Poland (two each), Afghanistan, Armenia, Denmark, Estonia, Greece, Indonesia, Iran, Mexico, Russian Federation, and Zambia (one each).

The analysis of all answers showed that only 78 participants (45.4\%) have had a lecture about smallpox during their medical school; interestingly, five specialists who began their medical school before the definitive eradication of smallpox (out of 14) hadn't had any lecture about smallpox. Nevertheless, more than half participants declared they had seen at least three images of smallpox and that they knew the natural history of the disease and its differential diagnosis. 114 participants $(66.3 \%)$ had no knowledge about potential therapies to use against smallpox. Predictably, about $90 \%$ of participants had knowledge about vaccination (Figure 1).

We compared basic smallpox knowledge between medical students and graduates (Table 1). As we were expecting, there was no statistically significant difference $(\mathrm{P}=0.22)$ between the two groups regarding question \#6, since, to date, smallpox eradication has been one of the biggest conquest achieved by humankind thanks to the massive $\mathrm{WHO}$ vaccination campaign. Interestingly, there was no significant difference $(\mathrm{P}=0.11)$ also over the answers to question \#1. This result demonstrated that smallpox hasn't been a major topic even during pre-eradication times, at least in developed countries, which are represented the most in our survey. We cannot underestimate this result considering that developed countries are major targets for bioterrorist attacks. The analysis of answers to questions \#2, \#3, \#4, and \#5 showed that current medical students lack of knowledge on basic clinical aspects of smallpox (\#2, $\mathrm{P}=0.0001 ; \# 3, \mathrm{P}=0.01$; \#4, $\mathrm{P}=0.00001)$ and about the possible availability of specific therapy to use to treat smallpox ( $\# 5, P=0.00002)$.

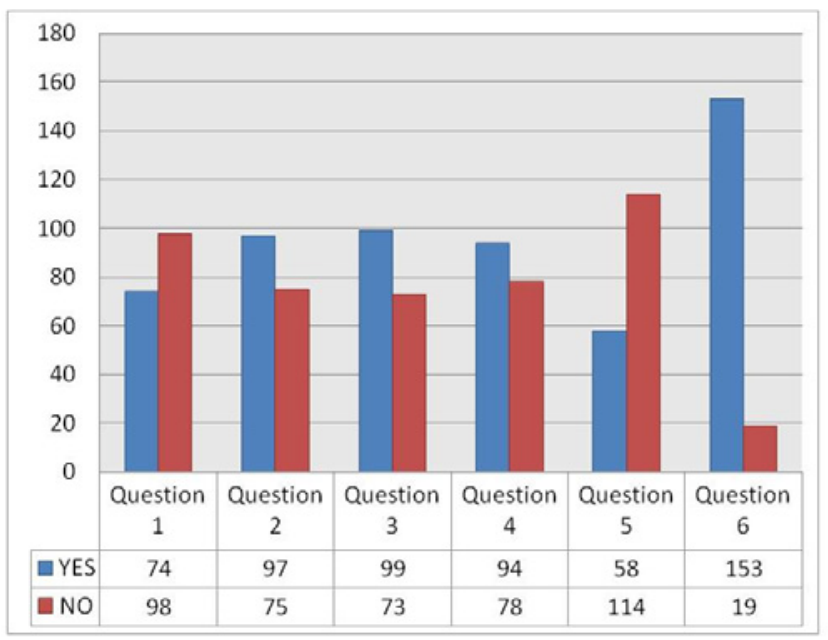

Figure 1: Trend of answers submitted by all participants

\begin{tabular}{|l|l|l|l|l|l|}
\hline \multirow{2}{*}{ QUESTION } & \multicolumn{3}{|l|}{$\begin{array}{l}\text { STUDENTS } \\
\mathbf{1 1 1}(\mathbf{6 4 , 5 \% )}\end{array}$} & \multirow{2}{*}{ GRADUATES } \\
\cline { 2 - 5 } & YES n (35,5\%) & NO n (\%) & YES n (\%) & NO n (\%) & \\
\hline $\mathbf{1}$ & $48(43,2 \%)$ & $63(56,8 \%)$ & $30(49,2 \%)$ & $31(50,8 \%)$ & 0,11 \\
\hline $\mathbf{2}$ & $52(46,9 \%)$ & $59(53,1 \%)$ & $45(73,8 \%)$ & $16(26,2 \%)$ & 0,0001 \\
\hline $\mathbf{3}$ & $58(52,2 \%)$ & $53(47,8 \%)$ & $41(67,2 \%)$ & $20(32,8 \%)$ & 0,01 \\
\hline $\mathbf{4}$ & $49(44,1 \%)$ & $62(55,9 \%)$ & $45(73,8 \%)$ & $16(26,2 \%)$ & 0,00001 \\
\hline $\mathbf{5}$ & $36(32,4 \%)$ & $75(67,6 \%)$ & $38(62,3 \%)$ & $23(37,7 \%)$ & 0,00002 \\
\hline $\mathbf{6}$ & $99(89,2 \%)$ & $12(10,8 \%)$ & $54(88,5 \%)$ & $7(11,5 \%)$ & 0,22 \\
\hline
\end{tabular}

Table 1: Comparison between students' and graduates' answers.

The small number of answers received (overall from students/ graduates living in a country different from Italy) represents a limitation of our study. Other limitations of our study is the lack of a standardization type question to check the accuracy of the yes/no answers (such as a photographic example in the survey to determine if the image was of smallpox lesions) and the absence of questions pertaining to the focus on other bioterrorism agents such as anthrax or $Y$. pestis. Nevertheless our findings should not be underestimated, but they should be considered as a starting point for further investigations, since to our knowledge this is the first example of a bioterrorismrelated survey among medical students and residents.

Although smallpox has been declared eradicated more than a quarter of a century ago, we still have to consider it as a global threat, provided the terrorist and bioterrorist attacks of September 2001 and the ongoing precarious worldwide political situation.

For this reason we decided to evaluate current knowledge of present and future medical population, asking only for real basic concepts that could be useful in the event of a bioterrorist attack (recognition of typical lesions, natural history, differential diagnosis, and treatment). Our findings support the hypothesis that since its eradication, there has not been any lecture on smallpox at universities, leading to a general decay of basic knowledge. These results should have a profound impact on both academic organisation and medical everyday practice.

\section{Acknowledgment}

We thank all students, residents, and physicians who participated in this study. 
Citation: Buonsenso D, Gargiullo L, Cataldi L, Ranno O, Valentini P (2011) Smallpox and Bioterrorism: History and Evaluation of Current State and Medical Knowledge. J Clinic Res Bioeth S3:001. doi:10.4172/2155-9627.S3-001

Page 5 of 5

\section{References}

1. Fenner F, Henderson DA, Arita I, Jezek Z, Ladnyi ID (1988). Smallpox and its eradication. Geneva: World Health Organization.

2. Esposito JJ, Sammons SA, Frace AM, Osborne JD, Olsen-Rasmussen M, et al. (2006) Genome sequence diversity and clues to the evolution of variola (smallpox) virus. Science 313: 807-812.

3. Dixon CW (1962). Smallpox. London: Churchill Ltd

4. Rotz LD, Cono J, Damon IK (2010). Smallpox as an Agent of Bioterrorism. In: Mandell, Douglas and Bennett's Principles and Practice of Infectious Diseases. $7^{\text {th }}$ ed. Churchill Livingstone Elsevier ; 39773981

5. Rao AR (1972). Smallpox. Bombay. India: Kothari Book Depot.

6. Sarkar JK, Mitra AC, Mukerjee MK, De SK (1973) Virus excretion in smallpox. 2. Excretion in the throat of household contacts. Bull World Health Organ 48: $523-527$.

7. Stier DM, Patel N, Bruch O, Holbrook KA (2008) Smallpox. In: Emergency Management of Infectious Diseases. Chin RL: Cambridge University Press. 443-449

8. Breman JG, Henderson DA (2002) Diagnosis and management of smallpox. N Engl J Med 346: 1300-1308.

9. Quenelle DC, Prichard MN, Keith KA, Hruby DE, Jordan R, et al. Synergistic efficacy of the combination of ST-246 with CMX001 against orthopoxviruses. Antimicrob Agents Chemother 51: 4118-4124

10. U.S. Food and Drug Administration. Product approval information.

11. http://www.bt.cdc.gov/agent/smallpox (accessed on March 1 $1^{\text {st }}, 2011$ ).

12. Fenner F (1993). Smallpox: emergence, global spread, eradication. Hist Philos Life Sci 15: 397-420.

13. Morens DM, Folkers GK, Fauci AS (2008) Emerging infections: a perpetual challenge. Lancet Infect Dis 8: 710-719.

14. Pead PJ (2003). Benjamin Jesty: new light in the dawn of vaccination. Lancet 362: 2104-2109

15. Jenner E. The origin of vaccine inoculation. London: Shury 1801.

16. Pennington H (2003) Smallpox and bioterrorism. Bull World Health Organ 81 762-767.

17. Rimoin AW, Mulembakani PM, Johnston SC, Lloyd Smith JO, Kisalu NK, et a (2010) Major increase in human monkeypox incidence 30 years after smallpox vaccination campaigns cease in the Democratic Republic of Congo. Proc Nat Acad Sci USA 107: 16262-16267.
18. Reed KD, Melski JW, Graham MB, Regnery RL, Sotir Mj, et al. (2004) The detection of monkeypox in humans in the Western Hemisphere. N Engl J Med 350: $342-350$

19. Chen N, Li G, Liszewski MK, Atkinson JP, Jahrling PB et al.(2005) Virulence differences between monkeypox virus isolates from West Africa and the Congo basin. Virology 340: 46-63.

20. Henderson DA (1999) The looming threat of bioterrorism. Science 283: 1279 1282.

21. McFadden G (2010). Killing a Killer: What Next for Smallpox? PLoS Pathog 6 : e1000727

22. (2006) Chemical-biological terrorism and its impact on children. American Academy of Pediatrics. Committee on Environmental Health and Committee on Infectious Diseases. Pediatrics 118: 1267-1278.

23. Vorobjev A (1994) "Criterion rating" as a measure of probable use of bioagents as biological weapons. Presented to Working Group on Biological Weapons Control of the Committee on International Security and Arms Control. Washington D.C National Academy of Sciences.

24. Longini IM Jr, Halloran ME, Nizam A, Yang Y, Xu S, et al.(2007) Containing a large bioterrorist smallpox attack: a computer simulation approach. Int J Infect Dis 11: 98-108.

25. Gani R, Leach S (2001) Transmission potential of smallpox in contemporary populations. Nature 414: 748-751.

26. Borio L, Hynes NA, Henderson DA (2010). Bioterrorism: an overview. In: Mandell, Douglas and Bennett's Principles and Practice of Infectious Diseases. 321. $7^{\text {th }}$ ed. Churchill Livingstone Elsevier. Philadelphia 3951-3963.

27. (2002) Public Health Preparedness: Progress and Challenges since Septembe $11^{\text {th }}, 2001$ - A Progress Report. Washington, D.C Trust for America's Health.

28. Massoudi MS, Barker L, Schwartz B (2003) Effectiveness of postexposure vaccination for the prevention of smallpox: Results of a Delphi analysis. J Infect Dis 188: 973-976

29. Barbera J, Macintyre A, Gostin L, Inglesby T, O'Toole T, et al. (2002) Largescale quarantine following biological terrorism in the United States. JAMA 286 2711-2717

30. Wehrle PF, Posch J, Richter KH, Henderson DA (1970) An airborne outbreak of smallpox in a German hospital and its significance with respect to other recent outbreaks in Europe. Bull World Health Organ 43: 669-679.

31. Vora S, Damon I, Fulginiti V, Weber SG, Kahana M, et al. (2008) Severe eczema vaccinatum in a household contact of a smallpox vaccinee. Clin Infect Dis 46: 1555-1561.
This article was originally published in a special issue, Bioethics: Politics handled by Editor(s). Dr. Miran Epstein, Queen Mary University of London, UK 